\title{
Ethylene Production by Bacteria
}

\author{
By S. B. PRIMROSE* AND M. J. DILWORTH† \\ Department of Soil Science and Plant Nutrition, \\ University of Western Australia, Nedlands, Western Australia 6009
}

(Received I 8 June I975; revised I September 1975)

\section{INTRODUCTION}

Soils held anaerobically at field capacity are known to produce large quantities of hydrocarbons, including ethylene, a plant hormone. Values as high as 75 p.p.m. have been recorded in the field (Smith \& Dowdell, 1974). Since ethylene is produced when plants are absent, but not when soils are autoclaved, the agents producing it are probably micro-organisms.

Lynch (1972) showed that specific substrates could be important for ethylene production in the soil, and that amendment with glucose and methionine allowed the isolation of two yeasts and Mucor hiemalis, which produced ethylene in pure culture. Subsequently, it was shown that $M$. hiemalis produced ethylene at a maximum rate under aerobic conditions, but produced none under anaerobic conditions (Lynch \& Harper, 1974). Although this is in general agreement with the results of other mycologists (Mapson, 1969), it is difficult to reconcile the activities of these organisms with ethylene production in waterlogged soils which appear to be highly anaerobic. However, ethylene production, under laboratory conditions, does not appear to require conditions as anaerobic as does methane evolution (Smith \& Restall, 1971): although some methane is produced at the same time as ethylene, the greatest methane production occurs after ethylene production has ceased.

Smith \& Cook (1974) showed that ethylene production in moist soils was not affected by heat treatments which were almost certainly fatal to $M$. hiemalis, and suggested that ethylene formation in soils was due largely to spore-forming bacteria. However, isolation of these bacteria was not attempted. A few strains of Pseudomonas solanacearum, pathogenic to bananas and tobacco, have been shown to form ethylene in culture (Freebairn \& Buddenhagen, I 964), but these are the only examples of ethylene-producing bacteria.

During the winter of 1974 , heavy rainfall over the wheat growing areas of South-Western Australia produced widespread crop damage from waterlogging. We describe the isolation of ethylene-producing bacteria from such waterlogged soils, and present some data on ethylene levels in them.

\section{METHODS}

Soil sampling. Samples of soil water were removed from $\mathrm{Io} \mathrm{cm}$ below the soil surface and placed immediately in $6 \mathrm{ml}$ bottles sealed with rubber serum caps (Suba-Seal; W. Freeman \& Co., Barnsley, Yorkshire). Approximately $5 \mathrm{~g}$ samples of waterlogged soils, from $10 \mathrm{~cm}$ below the surface, were taken similarly. All samples were kept in ice during transport to the laboratory and were analysed immediately on arrival.

Media. The potato extract-yeast extract-mannitol (YP) medium of Broughton \& Dilworth (1971) was used for the isolation of ethylene-producing bacteria from soil. For all other experiments, the defined medium of Brown \& Dilworth (1975) was used.

* Present address: Department of Biologial Sciences, University of Warwick, Coventry CV4 7AL.

$\dagger$ Present address: School of Environmental and Life Sciences, Murdoch University, Murdoch, Western Australia 6I53. 
Isolation of ethylene-producing organisms. Soil samples were diluted with sterile water and suitable dilutions spread on solidified YP medium. Plates were incubated both aerobically and anaerobically at $25{ }^{\circ} \mathrm{C}$ for 3 days.

Growth of cultures. Preliminary tests for ethylene production were done with cultures ( $10 \mathrm{ml}$ ) in $30 \mathrm{ml} \mathrm{McCartney} \mathrm{bottles} \mathrm{with} \mathrm{a} \mathrm{hole} \mathrm{punched} \mathrm{in} \mathrm{the} \mathrm{aluminium} \mathrm{cap,} \mathrm{which} \mathrm{were}$ incubated at room temperature (about $20^{\circ} \mathrm{C}$ ).

Flask cultures were grown at $30^{\circ} \mathrm{C}$ under aerobic and anaerobic conditions in $20 \mathrm{ml}$ defined medium in $250 \mathrm{ml}$ conical flasks sealed with rubber serum caps, and shaken at I 00 strokes/min for $96 \mathrm{~h}$ when there was no further increase in ethylene production. Serum caps or rubber cap inserts were sterilized with $70 \%(\mathrm{v} / \mathrm{v})$ ethanol to avoid the liberation of ethylene caused by heat sterilization.

Ethylene assay. Gas samples ( $\mathrm{I} \mathrm{ml}$ ) were withdrawn through the rubber seals and analysed using a Pye Unicam 104 chromatograph, with a $1.5 \mathrm{~m} \times 5 \mathrm{~mm}$ column of Porapak T, which was operated isothermally at $50{ }^{\circ} \mathrm{C}$, with nitrogen as the carrier gas and a flame ionization detector.

Reagents. L-Methionine was purchased from Sigma, Porapak T from Phase Separation Ltd, Queensferry, Flintshire, and the API 20 E diagnostic kit from API Laboratory Products, Rayleigh, Essex.

\section{RESULTS}

Wheat crops examined in the field near Brookton, Western Australia (Malebelling soil series, pH 6.2 to $6 \cdot 6,2 \cdot 32 \%$ organic carbon) showed extensive areas of chlorosis, but although the waterlogged areas were usually associated with the chlorosis the correlation was not perfect. Ethylene was detected in samples of gas from above the soil and in water from the waterlogged soils, but only in very small amounts in samples of gas from above soils which had been well drained in the field. The concentrations in the soil atmosphere in equilibrium with the soil water were calculated as indicated by Smith \& Restall (I97I), using an absorption coefficient for ethylene in water at $0{ }^{\circ} \mathrm{C}$ of 0.256 (Forsyth, 1964). The values obtained ranged from 0.2 to $2 \cdot 0$ p.p.m. Such concentrations have been shown to inhibit root elongation of various cereals (Smith \& Robertson, 1971). Plants from ethylenecontaining soils showed no sign of fungal infection but were obviously badly stunted.

Eighteen different bacterial colony types were observed on aerobically-grown YP plates and five on anaerobically-grown YP plates, three days after inoculation with soil samples. No fungal colonies were observed on either the aerobic or the anaerobic plates, even after 8 days' incubation. The 23 colony types were purified by restreaking and tested individually for ethylene production. Suitable controls 'with sterile media showed no ethylene production, while five of the isolates (B, E, G, P and S) produced significant amounts of ethylene after I $44 \mathrm{~h}$ incubation at $25{ }^{\circ} \mathrm{C}$ (Table $\mathrm{I}$ ). Three of the isolates were facultative anaerobes and could be isolated from either the aerobic or anaerobic plates.

The five ethylene-producing isolates were sent to two diagnostic laboratories without any indication of their origin. All these isolates were Gram-negative rods. Strain P was not identified as it failed to grow on nutrient agar, blood agar, chocolate-blood agar or in media supplemented with yeast extract or peptone. It grows only in the presence of potato extract, but the growth requirements are not known.

Both laboratories identified strains $B$ and $E$ as pseudomonads and strains $G$ and $S$ as enteric bacteria. One laboratory identified the latter strains as Enterobacter aerogenes and the other as Escherichia coli. By means of the API20E diagnostic system, we have confirmed the identification as $E$. coli. 
Table I. Ethylene production by five soil isolates grown in YP medium under air

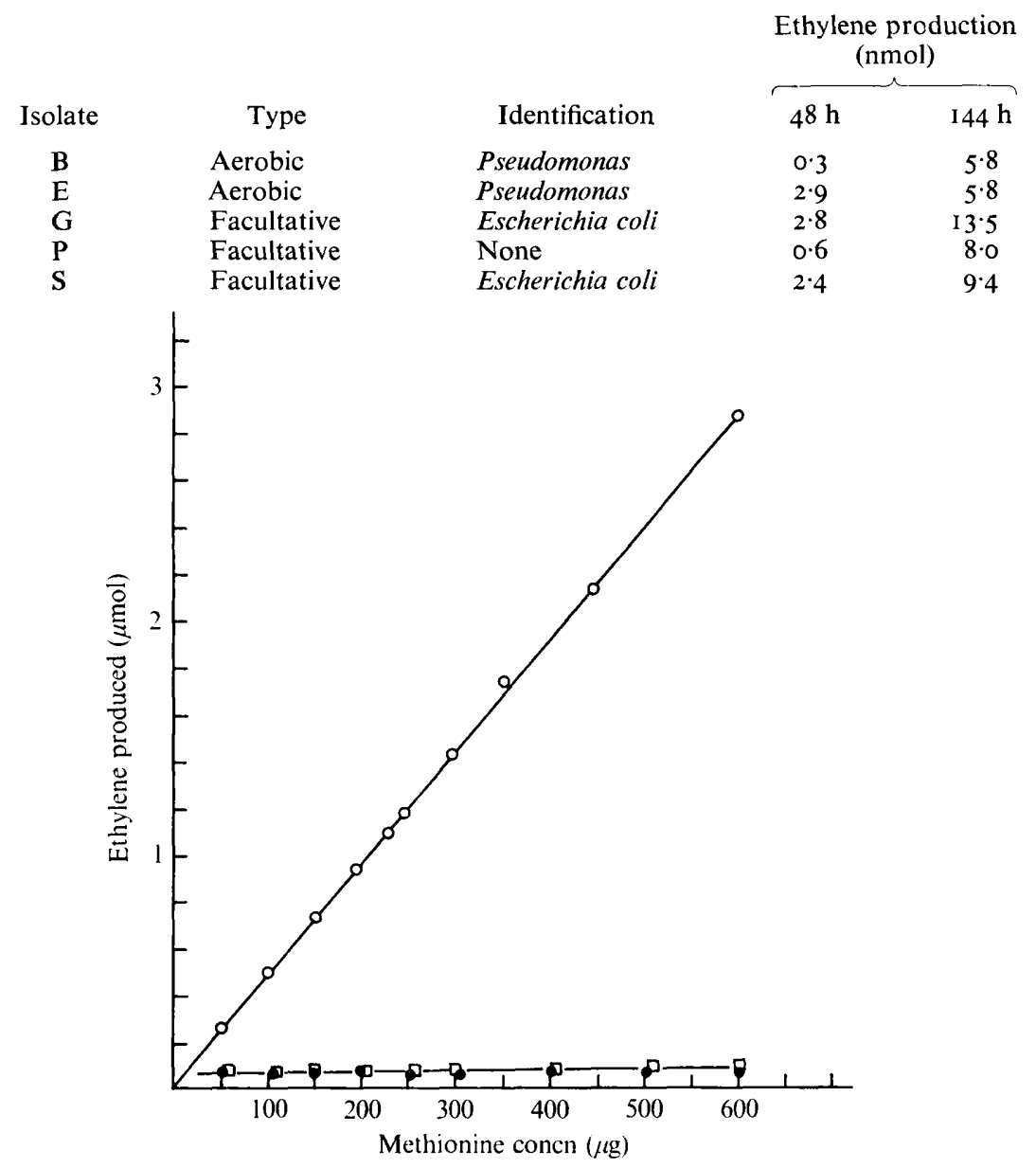

Fig. I. Ethylene production by isolate $G$ in $(O)$ aerobic and $(\bullet)$ anaerobic conditions. $(\square)$, uninoculated control.

After identification of two of the soil isolates as enteric bacteria, a range of other enteric bacteria was screened for ethylene production. All those tested produced ethylene but the final concentration, after $96 \mathrm{~h}$, was considerably less than that produced by soil isolate $\mathrm{G}$. Two species of Azotobacter, two of Bacillus, one strain of Photobacterium and one strain of Pseudomonas aeruginosa failed to produce detectable ethylene.

Methionine is generally considered as being the substrate for ethylene production. However, a wide range of other substrates has been suggested at various times, including serine, fumarate, pyruvate, acetate, succinate and malate (for review see Bird \& Lynch, 1974). When these various compounds were tested with isolate $G$, only methionine allowed ethylene production and the final yield of ethylene was proportional to the amount of methionine in the medium (Fig. I). As well as a requirement for an energy source, ethylene production showed a requirement for molecular oxygen, since none was formed under anaerobic conditions (Fig. I). 


\section{DISCUSSION}

The causes of damage to cereals by waterlogging may include ethylene effects, although more work is required to demonstrate this conclusively. Nevertheless, our finding of ethylene concentrations in soil water high enough to inhibit root elongation in cereals (Smith \& Robertson, 1971) suggests that it was a factor in the damage observed in Brookton soils. Since the production of ethylene from soils is correlated with their organic matter content (Smith \& Restall, I97I) and since the Brookton soils are low in organic matter, ethylene concentrations at the low end of the range for field soils are to be expected.

Although we isolated five different strains of bacteria capable of producing ethylene in pure culture, we cannot prove that they were responsible for its production in the field. Indeed, our cultures appear to produce ethylene in defined media under aerobic conditions only, while the soil from which they came was clearly anaerobic. Since ethylene could also be produced slowly in the YP media under anaerobic conditions, it is possible that a growth factor present in the richer medium permits anaerobic ethylene production. However, it is also possible that other bacteria in the soil were responsible for the production of ethylene anaerobically, or that the production of ethylene may only occur very close to the surface in such soils.

Smith \& Cook (I974) concluded, from the results of heat treatment and varying the water potential, that spore-forming bacteria were the most likely group of organisms to be producing ethylene in their soils. We also found that a soil suspension heated at $80{ }^{\circ} \mathrm{C}$ for I 5 min still contained organisms which could produce ethylene from media containing glucose, pyruvate and methionine, but that it took longer to produce ethylene under nitrogen than under air. If our isolates and those producing ethylene after heat treatment are the same, the conclusion that ethylene-producing bacteria are necessarily spore-forming would be unjustified. However, heating soil is a complex process and the heat treatment does not eliminate fungi as causative agents (Lynch, 1975).

Some caution must be used in extrapolating from the laboratory results to the field situation. In mixed soil populations, accumulation of ethylene indicates an excess of ethylene production over ethylene consumption, while in pure cultures it is possible to identify which organisms are ethylene-producing. Ethylene consumption is an aerobic process (Abeles et al., 1971), and ethylene production may occur in soil under aerobic conditions but remain undetected if the rate of consumption is equal to or greater than the rate of production. On the other hand, even a slow rate of production of ethylene under anaerobic conditions may cause an accumulation of ethylene if it cannot be oxidized at all in the absence of oxygen. Thus, the slow evolution of ethylene observed with soil suspensions under anaerobic conditions may be of significance in the field.

Despite our ignorance of the ecological significance of our ethylene-producing isolates, their discovery is still of interest. There is no commonly accepted mechanism of ethylene biosynthesis (Lynch, 1974) but the existence of bacteria with such activity should facilitate the isolation of mutants and analysis of pathways. Because the genetic systems of enteric bacteria are well understood it may be possible to identify the regulatory systems for ethylene biosynthesis, thus giving an insight into the control mechanisms for secondary metabolism in bacteria. 


\section{REFERENCES}

Abeles, F. B., Craker, L. E., Forrence, L. E. \& Leather, G. R. (197I). Fate of air pollutants: removal of ethylene, sulfur dioxide, and nitrogen dioxide by soil. Science, New York 173, 914-9I6.

BIRD, C. W. \& LYNCH, J. M. (I974). Formation of hydrocarbons by micro-organisms. Chemical Society Reviews 3, 309-328.

Broughton, W. J. \& Dilworth, M. J. (I97I). Control of leghaemoglobin in snake beans. Biochemical Journal 125, 1075-1080.

Brown, C. M. \& Dilworth, M. J. (1975). Ammonia assimilation by Rhizobium cultures and bacteroids. Journal of General Microbiology 86, 39-48.

Forsyth, W. E. (1964). Smithsonian Physical Tables, 9th edn. Washington, D.C.: Smithsonian Institute.

Freebairn, H. T. \& Buddenhagen, I. W. (1964). Ethylene production by Pseudomonas solanacearum. Nature, London 202, 3I3-3I4.

LYNCH, J. M. (1972). Identification of substrates and isolation of micro-organisms responsible for ethylene production in the soil. Nature, London 240, 45-46.

LyNCH, J. M. (I974). Mode of ethylene formation by Mucor hiemalis. Journal of General Microbiology 83 , 407 -4I I.

LYNCH, J. M. (I975). Ethylene in soil. Nature, London 256, 567-577.

LynCh, J. M. \& HARPER, S. H. T. (I974). Formation of ethylene by a soil fungus. Journal of General Microbiology 80, I 87-195.

MAPSON, L. W. (1969). Biogenesis of ethylene. Biological Reviews 44, 155-187.

Smith, A. M. \& CoOK, R. J. (1974). Implications of ethylene production by bacteria for biological balance of soil. Nature, London 252, 703-705.

Smith, K. A. \& Dowdell, R. J. (1974). Field studies of soil atmosphere. I. Relationships between ethylene, oxygen, soil-moisture content and temperature. Journal of Soil Science 25, 217-230.

Smith, K. A. \& Restall, S. W. F. (I971). The occurrence of ethylene in anaerobic soil. Journal of Soil Science 22, 430-443.

Smith, K. A. \& Robertson, P. D. (197I). Effect of ethylene on root extension of cereals. Nature, London 234, $148-149$. 